\title{
RAZVOJNO ZAOSTAJANJE PODSAHARSKE AFRIKE
}

Ključne besede: Podsaharska Afrika, države v razvoju, razvojni cilji tisočletja, regionalna geografija

\section{Uvod}

Podsaharska Afrika je izjemno raznolika svetovna regija, ki se ponaša z obsežnim naravnim bogastvom, velikimi človeškimi potenciali in bogato zgodovino. Toda zibelka človeštva je dandanes odrinjena na rob svetovnega dogajanja. Iz nje prihajajo pretežno slike in poročila o revščini, konfliktih, naravnih nesrečah, boleznih in drugih negativnih pojavih, ki prispevajo $\mathrm{k}$ izrazito neugodni podobi regije $\mathrm{v}$ svetu.

V Podsaharski Afriki živi že okrog osemsto milijonov prebivalcev, od katerih se jih skoraj polovica sooča s pogoji skrajne revščine. Države Podsaharske Afrike so nasploh med najbolj revnimi na svetu. Po podatkih Svetovne banke (Africa Development ..., 2008) je leta 2006 bruto domači proizvod (BDP) celotne regije znašal 744 milijard USD, kar je ustrezalo 28 odstotkom ustvarjenega BDP na Kitajskem ali 69 odstotkom BDP Brazilije oziroma 74 odstotkom BDP Rusije. Dohodki večine držav so zelo skromni, saj kar 56 odstotkov BDP v regiji prispevata gospodarstvi Južnoafriške republike in Nigerije. Povečujejo se tudi razlike med revnimi in bogatimi sloji. Številni Afričani so dandanes revnejši od svojih prednikov na sredini 20. stoletja. Soubbotina in Sheramova $(2000,25)$ navajata, da je leta 1965 povprečni dohodek na afriškega prebivalca ustrezal 14 odstotkom povprečja razvitih držav, medtem ko je trideset let pozneje dosegal le še 7 odstotkov. Nesporno dejstvo je, da Podsaharska Afrika pri zagotavljanju 
vsestranskega napredka močno zaostaja za drugimi svetovnimi regijami. V nadaljevanju bomo skušali prikazati trende na posameznih področjih razvoja in razloge zanje.

\section{Od poosamosvojitvenega optimizma do poraženk globalizacije}

Evropejci so dežele južno od Sahare začeli spoznavati šele v času razmaha oceanske plovbe in iskanja pomorske poti v Indijo, pozneje pa so $\mathrm{z}$ afriških obal prodirali vedno globlje v lovu na sužnje (Medved, 1978). Sužnji so bili kar dvanajst stoletij, začenši v 7. stoletju, glavni izvoz Podsaharske Afrike. S strani Evropejcev organizirana trgovina s sužnji z vrhuncem v 18. in 19. stoletju je bila tista, ki je najbolj grobo posegla $\mathrm{v}$ demografsko sestavo afriškega prebivalstva, močno prizadela lokalna in regionalna gospodarstva ter povzročila nestabilnost socialnih, političnih in okoljskih sistemov (Stock, 2004). Medtem ko je bila trgovina s sužnji omejena le na določena območja Podsaharske Afrike, je Evropejcem od osemdesetih let 19. stoletja uspelo razkosati veliko večino celine. Evropska oblast je na večini afriških ozemelj trajala samo šest do osem desetletij, vendar je v politični, ekonomski in družbeni geografiji Afrike povzročila globoke in trajne spremembe. Čeprav današnjega razvojnega zaostajanja regije ne gre pripisovati zgolj izkoriščevalskim kolonialnim odnosom, pa je nesporno, da so jo prav ti postavili v vlogo ponudnice poceni surovin in delovne sile (Pulsipher Mihelič, Pulsipher, 2002; Stock, 2004), ki jo je obdržala do danes. Dolgotrajni učinki kolonializma še vedno ostajajo pomemben razvojni dejavnik, vendar je še več tistih, ki izhajajo iz poosamosvojitvenega obdobja.

Gibanja za neodvisnost so se v Podsaharski Afriki močno okrepila po drugi svetovni vojni. Prva si je neodvisnost od evropskih kolonialnih sil leta 1957 pridobila Gana in postopoma so ji sledile še druge države. Večina držav južno od Sahare se je osamosvojila v šestdesetih letih 20. stoletja. Leta 1993 se je kot zadnja osamosvojila Eritreja, vendar je v tem primeru šlo za odcepitev od sosednje Etiopije po večletni državljanski vojni. V času osamosvajanja so ekonomisti in politični voditelji delili prepričanje, da bo Afrika končno imela korist od svojih naravnih virov in delovne sile ter do- 
živela modernizacijo in napredek (Pulsipher Mihelič, Pulsipher, 2002). S tem je bil povezan velik optimizem v petdesetih in šestdesetih letih 20. stoletja. V Severni Ameriki in Evropi se je v povojnem obdobju hitro povečeval obseg proizvodnje in potrošnje, zato je naraščalo tudi povpraševanje po surovinah iz Afrike in z njim vred so se višale tudi cene surovin. Sveže investicije so bile usmerjene $v$ odpiranje rudnikov in plantaž, ponekod pa tudi v vzpostavljanje industrijske proizvodnje za potrebe lokalnega afriškega prebivalstva. Toda rezultati teh naporov so bili pogosto slabi, saj sta razvojne strategije ovirala predvsem preslabo razvita infrastruktura in slabo upravljanje, medtem ko so svetovni trg preplavljale surovine iz drugih držav, sčasoma presegle povpraševanje in povzročile padec cen (Stock, 2004).

$Z$ leti je prvotni optimizem pojenjal in $\mathrm{v}$ osemdesetih letih 20. stoletja so bile novice že zelo slabe. Afriki ni uspevalo dosegati napredka, razplamtele so se posamezne državljanske vojne in sprožile valove beguncev, vlade so se prekomerno zadolževale, zaradi slabega vzdrževanja se je slabšala infrastruktura, kmetijska proizvodnja je stagnirala ali celo upadala, cene hrane in življenjskih potrebščin pa so presegle kupno moč povprečnega prebivalca (Pulsipher Mihelič, Pulsipher, 2002). V državah v razvoju se je tega obdobja oprijela oznaka »izgubljeno desetletje« (Global ..., 2002). V devetdesetih letih 20. stoletja so se po afriški celini širile državljanske vojne in epidemija AIDS-a. Mednarodne institucije, kot sta Mednarodni denarni sklad in Združeni narodi (ZN), so vlade in gospodarstva skušale stabilizirati $\mathrm{z}$ različnimi paketi pomoči, mirovnimi silami in gospodarskim prestrukturiranjem. Ob razmeroma skromnih pozitivnih učinkih na področju omejevanja korupcije in pretirane birokracije, manjšanja moči elit, večanja proračunskih prihrankov in odpravljanja monopolov so prav ti programi strukturnega prilagajanja zaostrili številne druge probleme. Izpostaviti velja zlasti povečevanje brezposelnosti in gospodarski upad, prav tako pa gospodarskim reformam ni uspelo pritegniti tujih naložb ali zmanjšati bremena dolgov. Revno prebivalstvo si je čedalje težje zagotavljalo preživetje in zdravstveno oskrbo, saj je varčevanje krnilo osnovne zdravstvene in izobraževalne storitve (Pulsipher Mihelič, Pulsipher, 2002). Če so v prvih desetletjih po drugi svetovni vojni v gospodarski rasti videli sredstvo za doseganje višje kakovosti življenja in ključ do rešitve svetovnih problemov, se je $\mathrm{v}$ ta namen $\mathrm{v}$ času globalizacije priporočalo še odpiranje trgov in pri- 
vatizacijo, dobro upravljanje in pravno državo (Vintar Mally, 2009). Vendar tudi globalizacija večini držav v razvoju ni prinesla želenega napredka, saj so se (z izjemo večine vzhodnoazijskih in nekaterih latinskoameriških držav) šibko in počasi vključevale v svetovno gospodarstvo. Tako se je delež Podsaharske Afrike v svetovni trgovini od konca šestdesetih let 20. stoletja samo še zniževal (Soubbotina, Sheram, 2000, 66). Še leta 1980 je bil afriški delež v svetovni trgovini 6 odstotkov, na začetku 21. stoletja pa le še okrog 2 odstotka, pri čemer se struktura izvoznega blaga ni bistveno spremenila (Abuka, 2005, 127). Države Podsaharske Afrike se tako uvrščajo med poraženke globalizacije, saj so jih pozitivni učinki v veliki meri zaobšli, zabeležile pa so tudi negativno gospodarsko rast - povprečna gospodarska rast BDP na prebivalca je v obdobju 1990-1999 znašala -0,7 odstotka. Bolj spodbudni so bili gospodarski trendi v prvih letih 21. stoletja. Povprečna rast BDP na prebivalca $v$ regiji je bila $v$ obdobju 2000-2006 z 2,0 odstotka ponovno pozitivna (Africa Development ..., 2008). Gospodarsko rast so $\mathrm{v}$ veliki meri spodbudile politične reforme, ugodne cene primarnih proizvodov ter večja stopnja varnosti in miru, zlasti na jugu in zahodu afriške celine (Assessing ..., 2009, 1). Pozitivni trendi so sovpadli tudi s krepitvijo mednarodne podpore medregionalni pravičnosti in zavezam trajnostnega razvoja.

Deset let po konferenci ZN o okolju in razvoju v Rio de Janeiru je dane zaveze obnovil svetovni vrh o trajnostnem razvoju, ki je leta 2002 potekal $\mathrm{v}$ Johannesburgu. Sklepni dokument $\mathrm{z}$ vrha je utrdil tudi podporo uresničevanju Milenijske deklaracije (United Nations Millennium Declaration), ki jo je leta 2000 v New Yorku sprejelo vseh takratnih 189 članic ZN (Road map ..., 2001). Deklaracija je na začetku 21. stoletja jasno izpostavila razvojne prioritete in tako napovedala boj revščini, lakoti, boleznim, nepismenosti, diskriminaciji žensk in degradaciji okolja. Na osnovi omenjene deklaracije so bili za obdobje 1990-2015 oblikovani tako imenovani Milenijski razvojni cilji oziroma razvojni cilji novega tisočletja (angl. Millennium Development Goals), prek katerih se kvantitativno in kvalitativno spremlja uresničevanje časovno opredeljenih zavez (Vintar Mally, 2009). V nadaljevanju bodo podrobneje ovrednoteni dosedanji rezultati pri doseganju poglavitnih ciljev v Podsaharski Afriki. 


\section{Socialno-ekonomsko zaostajanje držav Podsaharske Afrike}

V svetu, v katerem mednarodna trgovina raste hitreje od obsega svetovne proizvodnje in čedalje večji delež trgovine poteka med različnimi podjetji znotraj istih multinacionalk (Atlas ..., 2003, 22), se afriške države ne znajdejo najbolje. Njihov delež v svetovni trgovini upada, v izvozu pa prevladujejo surovine (s 40 odstotki izvoza, zlasti nafta) ter kmetijski pridelki in proizvodi (s 25 odstotki izvoza). Istočasno izvoz industrijskega blaga stagnira na okrog 30 odstotkih, kar je znatno manj kot pri drugih državah $v$ razvoju. $V$ večini primerov gre za proizvode $\mathrm{z}$ nizko dodano vrednostjo, pogosto za polproizvode (Gupta, Yang, 2006). Glavnina afriškega izvoza je bila že tradicionalno namenjena v industrializirane države, v novejšem času pa čedalje več tudi v azijske, zlasti v Indijo in na Kitajsko (že okrog četrtina afriškega izvoza), ki postajata tudi pomembni vlagateljici na afriški celini. Trgovanje med afriškimi državami ostaja skromno in obsega manj kot 10 odstotkov celotne trgovine (ibid.). Tako kot $\mathrm{v}$ zgodovini so tudi danes afriške države bolj povezane s preostalim svetom kot med seboj.

Poleg kolonialne zgodovine in sodobnih svetovnih trgovinskih vzorcev so razvojno zaostajanje Podsaharske Afrike zakrivile tudi številne državljanske vojne in politični kaos. $\mathrm{V}$ času kolonializma umetno začrtane državne meje ne upoštevajo verskih in etničnih razlik, zato veliko število konfliktov ne preseneča. Stock $(2004,137)$ za obdobje 1960-2002 navaja več kot 85 uspelih državnih udarov v 35 afriških državah in še mnogo več neuspelih. Na desetine spopadov je afriške države fragmentiralo na veliko frakcij in strani, ki se borijo za prevlado. $V$ številnih državah (dandanes na primer v Somaliji) so notranji konflikti oslabili državo in centralno vlado do te mere, da ni sposobna zagotavljati osnovnih storitev v državi. Po mnenju številnih kritikov so $\mathrm{v}$ osrčju vseh afriških problemov prav politične elite, saj so v zadnjih štirih desetletjih v svojo korist izrabljale gospodarske dobičke celine (Mbeki, 2005). Drugi vzroki za gospodarsko zaostajanje Podsaharske Afrike so enaki kot drugod v državah v razvoju: visoka stopnja zadolženosti, korupcija, šibkost institucij, slaba infrastruktura, neugodnost mednarodnega trgovinskega sistema, nizka stopnja izobraženosti in slabo zdravstveno stanje prebivalstva, neugodne naravnogeografske razmere in 
podobno (Vintar Mally, 2009). Končni rezultat takšnih razmer je dejstvo, da Podsaharska Afrika s približno 12 odstotki svetovnega prebivalstva dandanes prispeva k svetovnemu BDP-ju le okrog 1,5 odstotka (World Development ..., 2008). Gospodarstva so na splošno premalo razvejena, saj se državam ni uspelo v večji meri industrializirati. Izvoz blaga (rud, nafte in kmetijskih pridelkov) ni neugoden le zaradi nizke dodane vrednosti, ampak tudi zaradi podvrženosti povpraševanju in nihanju cen na svetovnem trgu. Pri kmetijskih pridelkih se temu pridruži še izpostavljenost ujmam, boleznim in škodljivcem, ki lahko oklestijo pridelke in povzročijo izpad dohodka. Za afriško tržno kmetijstvo so velika prepreka tudi tržne ovire in kmetijske subvencije v razvitih državah.

Večina afriškega prebivalstva se preživlja s samooskrbnim kmetijstvom na malih kmetijah. Produktivnost je običajno nizka zaradi izčrpavanja prsti, dolgotrajne uporabe nespremenjenih vrst semen, skromne uporabe gnojil ter omejenega dostopa do kreditov in drugih tržnih spodbud. Po hektarskih donosih je Afrika na svetovnem repu, saj je na primer leta 2001 pridelala v povprečju $1.230 \mathrm{~kg}$ žita na hektar, medtem ko so ga v Latinski Ameriki pridelali $3.040 \mathrm{~kg}, \mathrm{v}$ Aziji $3.090 \mathrm{in}$ v EU $5.470 \mathrm{~kg}$ na hektar (African ..., 2005, 34). Z izobraževanjem kmetov in širjenjem učinkovitih namakalnih sistemov bi lahko bistveno povečali donose, samooskrbno kmetijstvo pa bi lahko postalo gonilo splošnega napredka. K odpravljanju revščine namreč po mnenju strokovnjakov ZN (Human ..., 2003) najbolj učinkovito prispeva prav gospodarska rast, ki temelji na delovno intenzivnih dejavnostih $\mathrm{v}$ večjem delu države, kar kmetijstvo zagotovo je. Za zmanjševanje revščine so zelo pomembne tudi državne naložbe v človekov razvoj - v zdravstvo, šolstvo, prehrano, oskrbo z vodo ipd. Prav pri odpravljanju revščine je bilo v Podsaharski Afriki v zadnjih letih doseženega (pre)malo napredka, zato bo do leta 2015 morebiti uspelo prepoloviti delež revnega prebivalstva le manjšemu številu držav. Odpravljanje revščine je praviloma pogojeno z zagotavljanjem polne in produktivne zaposlitve, toda zaradi nizkih plač dandanes tudi zaposlitev ne ščiti pred revščino. V Podsaharski Afriki se med izrazito revne uvršča kar polovica vseh delavcev, saj živijo v gospodinjstvih, katerih prihodki na člana ne dosegajo niti 1 USD na dan (The Millennium ..., 2008). 
Revno podsaharsko prebivalstvo je $\mathrm{v}$ zadnjih letih močno prizadela rast cen hrane, kar velja zlasti za revno mestno prebivalstvo in podeželsko prebivalstvo brez obdelovalnih površin. Poraba vse večjega deleža dohodkov za nakup hrane krči razpoložljiva sredstva za izobraževanje in zdravstveno oskrbo. Prizadeti so tudi mali kmetje, saj višje cene goriv zvišujejo cene gnojil in uvoženega blaga (The Millennium ..., 2008, 6). Afrika je neto uvoznica hrane že od leta 1980, ko je prebivalstvena rast začela prehitevati rast obsega kmetijske proizvodnje (African ..., 2005). Posledično je prehranska varnost držav izpostavljena tako nihanju cen hrane kakor tudi nihanju cen nafte in škodam zaradi podnebnih sprememb. Občutljivost je še večja zaradi velike odvisnosti afriškega kmetijstva od izdatnosti in razporeditve padavin, saj so deleži namakalnih površin zelo skromni. Občasno v Podsaharski Afriki izbruhnejo večje lakote, pogojene z izrednimi dogodki (suše, konflikti, slaba distribucija hrane ...), a določen delež prebivalstva je stalno podhranjen. Eden glavnih pokazateljev razmer so ocene deleža podhranjenih otrok do petega leta starosti. Gre za najbolj ranljivo skupino prebivalstva, v kateri podhranjenost $\mathrm{v}$ kombinaciji $\mathrm{z}$ izčrpanostjo zaradi infekcijskih bolezni in pomanjkljivo zdravstveno oskrbo zakrivi najmanj polovico smrti (The Millennium ..., 2005). Spodbudno je, da se je v obdobju 1990-2006 delež podhranjenih med otroki znižal z 32 na 28 odstotkov (The Millennium ..., 2008, 10). Kljub temu ostaja Podsaharska Afrika takoj za Južno Azijo druga najbolj problematična svetovna regija in bistveno preveč oddaljena od cilja prepolovitve deleža lačnega prebivalstva do leta 2015.

Med zelo pomembnimi razvojnimi cilji tisočletja so tudi cilji zniževanja smrtnosti otrok (za dve tretjini v obdobju 1990-2015) in porodnic (za tri četrtine v obdobju 1990-2015). Oba vodilna kazalnika v Podsaharski Afriki izkazujeta le skromen napredek. V tej regiji je možnost, da ženska umre $\mathrm{v}$ času nosečnosti ali zaradi zapletov ob porodu, kar $1: 22$, medtem ko v razvitih državah razmerje znaša $1: 7.300$ (The Millennium ..., 2008, 25). Visoka umrljivost je povezana s pomanjkljivo zdravstveno oskrbo, saj pri večini porodov (55 odstotkov) ni prisotnih oseb s kakršno koli zdravstveno izobrazbo (Assessing ..., 2009). Čeprav se je v obdobju 1990-2006 smrtnost otrok do petega leta starosti znižala s 184 na 157 od 1000 živorojenih, je to še vedno daleč najvišja stopnja smrtnosti na svetu, ki za dvakrat presega tisto v drugouvrščeni Južni Aziji (81 smrti otrok na 1000 živorojenih). 
Za primerjavo, $v$ razvitih državah do petega leta starosti v povprečju umre 6 od 1000 otrok (The Millennium ..., 2008, 20). V zadnjih letih je bilo še najbolj uspešno cepljenje otrok proti ošpicam, saj je v Podsaharski Afriki zmanjšalo število smrtnih primerov zaradi te bolezni za 91 odstotkov (ibid.). Poleg pljučnice, diareje, malarije in AIDS-a so ošpice ena od bolezni, ki skupaj povzročijo okrog polovico smrti otrok. Te najpogostejše bolezni bi bilo mogoče preprečiti ali pozdraviti že z razmeroma nizkimi stroški (The Millennium ..., 2005), tako pa se je v preučevanem obdobju v nekaterih podsaharskih državah smrtnost otrok celo povečala, kot na primer zaradi epidemije HIV/AIDS-a v predelih Južne Afrike in malarije v delih Zahodne Afrike (Assessing ..., 2009).

Zmanjšanje smrtnosti otrok bistveno prispeva $\mathrm{k}$ daljšanju pričakovane življenjske dobe, ki jo lahko novorojenec pričakuje v danih okoliščinah. Tako kot smrtnost otrok so tudi izračuni pričakovane dolžine življenja izrazito sintezni, saj neposredno odražajo številne vidike blaginje, vključno $\mathrm{z}$ dohodki in prehrano, kakovostjo okolja, dostopnostjo zdravstvenih storitev, primerne pitne vode in sanitarij (Soubbotina, Sheram, 2000; Indicators ..., 2001). Novorojenec v Podsaharski Afriki je leta 2005 lahko pričakoval, da bo živel 49,6 leta (v Sloveniji 77,4 leta). Države južno od Sahare po tem kazalniku zasedajo zadnjih 34 mest na svetovni lestvici. Ljudje umirajo najmlajši v Zambiji (40,5 leta), in to v povprečju za polovico mlajši od Japoncev, ki s povprečjem 82,3 leta živijo najdlje na svetu (Human ..., 2007). Po ocenah je smrtnost zaradi AIDS-a na začetku 21. stoletja povprečje afriških držav znižala s 54 na 48 let. V posameznih državah je pričakovana življenjska doba upadla za več kot 10 let, kot na primer v Južnoafriški republiki, Tanzaniji in Bocvani (The World Health ..., 2004, 6). Po zaslugi programov preprečevanja je število novookuženih v zadnjih letih nekoliko upadlo, zdravljenje s protivirusnimi zdravili pa je znižalo tudi število smrtnih primerov. Kljub temu v Podsaharski Afriki živi kar 68 odstotkov vseh okuženih, med katerimi z 61 odstotki prednjačijo ženske. Najbolj prizadete so države Južne Afrike, v katerih je leta 2005 delež okuženega odraslega prebivalstva presegal 15 odstotkov, v Svaziju pa celo 33 odstotkov (AIDS epidemic ..., 2007). Bolezen spreminja prebivalstveno sliko in pričakovano življenjsko dobo, povzroča velike socialno-ekonomske izgube zaradi umiranja mladega, delovno aktivnega prebivalstva, ustvarja milijone ne- 
preskrbljenih sirot ter preusmerja čas, denar in energijo v preprečevanje in zdravljenje bolezni namesto $\mathrm{v}$ izobraževalni sistem in preprečevanje drugih bolezni, kot so bilharcija, malarija, rečna slepota in kolera, ki ogrožajo mnogo višji delež prebivalstva (Pulsipher Mihelič, Pulsipher, 2002). Večina Podsaharske Afrike leži v tropskem pasu, kjer so idealna gojišča za različne prenašalce bolezni (muhe, komarje, bolhe, polže itd.). Prebivalstvo je tem boleznim izpostavljeno toliko bolj, ker živi pretežno na podeželju, v veliki odvisnosti od narave in $\mathrm{v}$ bližini stoječih vod ter rek kot potencialnih virov okužb (de Blij, Muller, 1997). V zadnjih letih je mogoče zaznati nekaj več napredka pri preprečevanju okužb z malarijo, zlasti po zaslugi programov distribucije mrež, pa tudi povečanega zatiranja komarjev, medtem ko je pri zagotavljanju zdravil obolelim manj uspeha (The Millennium ..., 2008, 32). Po poročilih Svetovne zdravstvene organizacije (World Malaria ..., 2008) za posledicami malarije letno umre okrog milijon prebivalcev, od tega je 91 odstotkov smrtnih primerov prav v Podsaharski Afriki. Ocenjuje se, da samo malarija vsako leto gospodarsko rast v regiji upočasni za 1,3 odstotka (Africa - Up in smoke, 2005), kar ni le posledica smrtnosti, temveč tudi zmanjšane produktivnosti obolelih oziroma njihove nezmožnosti za delo ter dovzetnosti za druge infekcijske bolezni zaradi slabše odpornosti.

Za zmanjševanje revščine in doseganje drugih razvojnih ciljev je izjemnega pomena tudi dvig izobrazbene ravni. Naložbe v prebivalstvo, njegovo zdravje, znanje in sposobnosti niso pomembne le $\mathrm{z}$ vidika pospeševanja človekovega razvoja, temveč se v državah v razvoju štejejo tudi za visoko donosne (Hardi in drugi, 1997), saj lahko igrajo vlogo izenačevalca možnosti in pospeševalca gospodarske rasti ter učinkovitosti (Human ..., 2005, 69). Primarni cilji na področju izobraževanja obsegajo vključevanje vseh prebivalcev $\mathrm{v}$ osnovno izobraževanje in zmanjševanje nepismenosti odraslih (Indicators ..., 2001, 43). Med osmimi poglavitnimi razvojnimi cilji tisočletja je tudi cilj doseganja osnovnošolske izobrazbe za vse otroke do leta 2015, kar bi dolgoročno odpravilo tudi problem nepismenosti. Čeprav se Podsaharska Afrika med vsemi svetovnimi regijami po izobrazbenih kazalnikih uvršča na zadnje mesto, je bil od leta 1990 vendarle dosežen znaten napredek. Tako je vpis v osnovno šolo do leta 2005 s 54 odstotkov narasel na 71 odstotkov (The Millennium ..., 2008, 12), na več kot 60 odstotkov pa se je zvišal tudi delež pismenega odraslega prebivalstva (Human ..., 2007). 
Kljub temu okrog 38 milijonov otrok v Afriki še vedno ne hodi v šolo, kar je približno polovica vseh otrok na svetu, ki so prikrajšani za osnovno izobrazbo. Posebej problematično je opuščanje šolanja, saj je leta 2005 osnovno šolanje v Podsaharski Afriki dokončala le okrog polovica generacije. Med vzroki za opustitev šolanja je tudi pozen začetek obiskovanja osnovne šole, zaradi česar so v poznejših letih mladi pod pritiskom, da si poiščejo službo ali ustvarijo družino, kar velja zlasti za dekleta (Assessing ..., 2009). Dekleta imajo večje težave $\mathrm{z}$ vpisom in prej opuščajo izobraževanje predvsem $v \mathrm{Za}$ hodni in Srednji Afriki. Suša, pomanjkanje hrane, oboroženi konflikti, neregistrirana rojstva, otroško delo in HIV/AIDS prispevajo k nizkemu vpisu in opuščanju šolanja tako pri fantih kot dekletih, vendar imajo dokazano resnejše posledice za dekleta (The Millennium ..., 2008, 17). Zagotavljanje enakosti med spoloma je tesno povezano z zagotavljanjem dostopnosti osnovnošolskega in srednješolskega izobraževanja za oba spola. Pretekle izkušnje kažejo, da se je izobraževanje deklic hitro in neposredno odrazilo v boljši prehranjenosti in zdravstvenem stanju družin, padanju rodnosti, zmanjšanju revščine in vsesplošni učinkovitosti (Road map ..., 2001, 20), predvsem z vidika njihove večje gospodarske in družbene vključenosti. Žal je v regiji še vedno večji delež nepismenih med dekleti, pa tudi stopnje osnovnošolskega in srednješolskega vpisa so nižje kot pri fantih. V državah južno od Sahare je srednješolska izobrazba dostopna le vsakemu četrtemu v generaciji, medtem ko se na tej stopnji v državah v razvoju nasploh šola 54 odstotkov generacije, v razvitih državah pa kar 92 odstotkov (The Millennium ..., 2008, 14). Večini podsaharskih držav do leta 2015 ne bo uspelo doseči zastavljenih izobrazbenih ciljev, kar bo dolgoročno slabilo njihove razvojne možnosti, zlasti v primerjavi s konkurentkami iz kroga držav v razvoju.

V zadnjih letih zbuja nekaj več upanja za razvojni preboj afriške celine širjenje uporabe mobilne telefonije in internetnih storitev. V Afriki so leta 2006 zabeležili več kot 60 milijonov novih naročnikov mobilne telefonije in skoraj v vseh državah je njihovo število že preseglo število naročnikov stacionarne telefonije. Konec leta 2006 je mobilni telefon imelo že 22 odstotkov afriških prebivalcev, stacionarnega pa le trije odstotki. S tehnološkim razvojem in uporabo brezžičnih širokopasovnih tehnologij se odpirajo nove priložnosti za zmanjšanje komunikacijskega prepada med državami v razvoju in razvitimi državami. Vendar je ponudba širokopasov- 
nih storitev, ki je spodbudila množično rabo interneta $\mathrm{v}$ razvitih državah, v Podsaharski Afriki zaenkrat še zelo skromna (The Millennium ..., 2008, 48). Obetajoče je zlasti dostopanje do svetovnega spleta prek mobilnih telefonov, ki zaobide potrebo po osebnem računalniku, saj se ta slabše vključuje $\mathrm{v}$ tradicionalno afriško kulturo s poudarkom na govorni komunikaciji (African ..., 2005). Že sedaj je mogoče zaznati, da so v zadnjih nekaj letih mobilni telefoni komunikacijsko povezali Afričane bolj kot vsa v preteklih stoletjih zgrajena infrastruktura.

Kljub nekaterim pomembnim dosežkom je splošni socialno-ekonomski napredek v regiji prepočasen, da bi lahko učinkovito zmanjšal razvojni zaostanek za gospodarsko razvitimi deli sveta. Temu se pridružuje še povečevanje razlik med afriškim podeželjem in mesti, pa tudi med bogatimi elitami in najrevnejšimi sloji prebivalstva. Medtem ko se prva skupina ponaša z življenjskim slogom, primerljivim z drugimi bogatimi po svetu, pa druga živi v začaranem krogu skrajne revščine, kakršne razviti svet že davno ne pozna več.

\section{Zagotavljanje okoljske trajnosti}

Zagotavljanje okoljske trajnosti je eden najpomembnejših razvojnih ciljev tisočletja. Dolgoročno je za uspešen vsestranski razvoj ključno, da se odvija v okviru nosilnih zmogljivosti okolja. Po izračunih ekološkega odtisa (Living ..., 2008) so pritiski na okolje v Podsaharski Afriki kot celoti in tudi v večini držav zaenkrat še nižji od nosilnih zmogljivosti okolja. Toda v želji po nadaljnjem gospodarskem razvoju se bodo tudi te države morale kmalu soočiti z omejitvami. Posledice človekovega nepremišljenega ravnanja se že sedaj kažejo v degradaciji okolja v posameznih delih regije. Med njimi velja omeniti zlasti deforestacijo, dezertifikacijo, odmiranje koralnih grebenov, negativne posledice podnebnih sprememb (dvig morske gladine, spremembe v razpoložljivosti vodnih virov, ekstremni vremenski dogodki itd.), izgubljanje biotske raznovrstnosti, nepovratno degradacijo prsti ipd.

Med bolj perečimi problemi Podsaharske Afrike so pričakovane posledice podnebnih sprememb. S povprečnim izpustom ene tone ogljikovega 
dioksida na prebivalca (primerjalno znaša izpust držav OECD kar 11,5 ton na prebivalca) prispevajo obravnavane države h globalnim emisijam toplogrednih plinov le 2,3 odstotka (Human ..., 2007). Čeprav nobena država ni med največjimi onesnaževalkami, bodo države Podsaharske Afrike med bolj prizadetimi deli sveta. Največji vplivi se pričakujejo na obrobju puščav in v savanah, ki naj bi postale bolj vroče in suhe, $\mathrm{z}$ bolj pogostimi in hudimi sušami ter upadom vode v rekah in jezerih (Stock, 2004, 83). Bolj sušni naj bi tako postali Sahel, deli Vzhodne Afrike, vključno z Jezerskim višavjem, in (pol)sušna območja Južne Afrike (ibid., 104). Po drugi strani pa naj bi območja z vlažnim podnebjem postala še bolj vlažna in topla, kar je idealno za rast populacij komarjev in drugih insektov ter posledično povečano pojavnost malarije in drugih bolezni, ki jih prenašajo (ibid., 83). Ob že obstoječih težavah so to problemi, ki bodo izjemno otežili položaj podsaharskih držav, saj je sposobnost prilagajanja njihovih (revnih) prebivalcev in gospodarstev zelo omejena. Med najbolj perečimi problemi bo v določenih delih regije pomanjkanje pitne vode, ki pa je (z izjemo sušnih delov) bolj posledica pomanjkljive ali neobstoječe vodne infrastrukture. Leta 2006 je imelo zagotovljen dostop do ustrezne pitne vode le 58 odstotkov podsaharskega prebivalstva, še slabše pa so sanitarne razmere, saj ima urejene ustrezne sanitarije le 31 odstotkov prebivalstva (The Millennium ..., 2008, 40). Razmere so praviloma mnogo slabše na podeželju in v barakarskih naseljih, v katerih živi več kot 60 odstotkov urbanega prebivalstva v regiji ( $v$ državah $v$ razvoju le tretjina urbanega prebivalstva) (The Millennium ..., $2008,43)$ in se sooča $z$ bistveno slabšimi bivalnimi razmerami od prebivalcev azijskih ali latinskoameriških barakarskih naselij. Čeprav je v mestih leta 2005 živelo le okrog 35 odstotkov prebivalcev Podsaharske Afrike (svetovno povprečje znaša 49 odstotkov) (Human ..., 2007), pa rast mest prehiteva zmožnost zagotavljanja potrebne infrastrukture in zaposlitev za novo prebivalstvo.

Prebivalstvena rast je zaskrbljujoča tudi $\mathrm{z}$ vidika izčrpavanja naravnih virov na afriški celini. Krčenje afriških gozdov je posledica povečevanja obsega obdelovalnih površin in povpraševanja po gorivih zaradi prebivalstvenega pritiska, v manjši meri pa tudi komercialne sečnje. Po ocenah naj bi bilo do leta 2000 izkrčenih 3 milijone $\mathrm{km}^{2}$ ali več kot 60 odstotkov prvotnih tropskih deževnih gozdov v Podsaharski Afriki (Pulsipher Mihelič, 
Pulsipher, 2002), ki so prava zakladnica planetarne biotske raznovrstnosti. V desetletju 1990-2000 je prav ta regija dosegala najhitrejšo deforestacijo na svetu, kar velja zlasti za države ob Gvinejskem zalivu, Sahelske države, Burundi, Ugando, Ruando, Zambijo, Zimbabve in Malavi (Vintar Mally, 2009). Širjenje obdelovalnih površin na račun gozdnih se odvija tudi zaradi izčrpavanja prsti na obstoječih obdelovalnih površinah. V preteklosti je bilo v Afriki skupno izgubljenih že približno toliko površin (303 milijone ha), kot jih je trenutno v obdelavi (307 milijonov ha), predvsem zaradi erozije, zaslanjevanja na namakalnih površinah in izčrpavanja hranil, na katerem temelji požigalniški način obdelovanja zemljišč (World Development ..., 2003, 86). S pritiski na naravne vire, zlasti vodo in vegetacijo, pa je v polsušnih predelih Podsaharske Afrike povezana tudi dezertifikacija, ki jo dodatno zaostrujejo podnebne spremembe. Konec obdobja kolonializma je hitra rast človeške in živalskih populacij v Sahelu in na drugih območjih suhe savane poljedelce in živinorejce spodbujala $\mathrm{k}$ širjenju na obrobna območja. Degradacija zaradi pretirane paše živine ter razgaljanja prsti z oranjem, požari in drugimi nepremišljenimi posegi je sovpadla $\mathrm{z}$ znižanjem količin padavin (v Sahelu v obdobju 1961-1990 kar za 30 odstotkov) in povzročila širjenje puščav (Stock, 2004). Dezertifikacija ogroža predvsem obrobje Sahare, Kalaharija, Namiba in Afriškega roga.

V Podsaharski Afriki živi na občutljivih območjih, kot so sušna območja brez možnosti namakanja, območja s prevlado obdelanih pobočij, območja občutljivih gozdnih ekosistemov in za kmetijsko obdelavo slabo primernih prsti, kar okrog 40 odstotkov prebivalstva. Kmetovanje navedene površine dodatno izpostavlja degradaciji, eroziji, poplavam in plazovom (World Development ..., 2003, 60), prebivalce pa spreminja v okoljske begunce. Občutljiva območja postajajo čedalje gosteje poseljena zaradi prebivalstvene rasti, agrarne prenaseljenosti na boljših zemljiščih, konfliktov in pogosto tudi apetitov tržnega kmetijstva po bolj kakovostnih zemljiščih ter posledičnega potiskanja revnih malih kmetov na manj ugodna območja. Vlade držav prepogosto namenjajo premalo pozornosti samooskrbnemu kmetijstvu in izobraževanju kmetov, zato revni v boju za vsakodnevno preživetje nehote povzročajo okoljsko škodo, ki pa povratno ogroža njihovo preživetje. Udejanjanje trajnostnega razvoja v Podsaharski Afriki zato ne bo možno brez sonaravnega kmetijstva. 


\section{Sklep}

Uravnotežen ekonomski, socialni in okoljski razvoj bo v prihajajočih desetletjih najtežje zagotavljati prav v najrevnejših državah sveta, kamor se uvršča tudi večina držav Podsaharske Afrike. V želji po zmanjševanju socialno-ekonomskega zaostanka za gospodarsko razvitimi utegnejo te države zapostavljati skrb za okolje. Kratkoročno se učinki takšnih razvojnih strategij sicer ne zdijo problematični, dolgoročno pa samo še slabšajo možnosti za doseganje vsesplošne blaginje. Pri zmanjševanju razvojnega zaostanka bo podsaharske države še dodatno ovirala napovedana prebivalstvena rast. Po ocenah ZN (UNPD, 2005) naj bi se do leta 2050 število prebivalcev v regiji najmanj podvojilo, $v$ določenih državah (na primer Uganda, Niger, Kongo, Burundi, Gvineja Bissau, DR Kongo, Liberija, Čad in Mali) pa celo več kot potrojilo. Takšna rast ne pomeni le velikega izziva za zagotavljanje zaposlitve in ustrezne kakovosti življenja (od bivališč in širjenja infrastrukture do izobraževanja in zdravstvene oskrbe), ampak tudi velik pritisk na omejene naravne vire, ki so skromnejši zlasti na sušnih in polsušnih območjih. Nalogo otežuje dejstvo, da imajo afriške države že ob obstoječem številu prebivalstva velike težave pri zagotavljanju višje kakovosti življenja.

V preteklih desetletjih je celina nedvomno napredovala na številnih področjih, zlasti na gospodarskem in političnem, države pa se trudijo tudi na področju doseganja razvojnih ciljev tisočletja. Na podlagi predstavljenega stanja in trendov lahko ugotovimo, da večini držav Podsaharske Afrike do leta 2015 ne bo uspelo izpolniti zadanih ciljev. Po bolj optimističnem začetku 21. stoletja še ni povsem jasno, v kolikšni meri bo njihov nadaljnji razvoj prizadet zaradi gospodarske in finančne krize, ki je svet zajela konec leta 2008. Ta utegne povzročiti tudi stagnacijo ali upadanje razvojne pomoči s strani razvitih držav. Razvojna pomoč je bila že do sedaj bistveno preskromna in $\mathrm{v}$ zadnjih letih se njen obseg ni znatno povečal, če ne upoštevamo odpisa dolgov in humanitarne pomoči. Glede na poglabljanje razvojnega zaostanka in povečevanje neenakosti tudi znotraj afriških držav bo $\mathrm{v}$ prihodnosti potrebna večja in bolj premišljena mednarodna pomoč ter spodbujanje pravičnejše svetovne trgovine. Na nemirni afriški celini pa bo treba krepiti zlasti mir in stabilnost, saj konflikti spodkopljejo že tako težko pridobljene dosežke človekovega razvoja. 


\section{SEZNAM VIROV IN LITERATURE}

Abuka, C., Infrastructure, Regional Integration and Growth in Africa, v: Africa in the World Economy: The National, Regional and International Challenges, The Hague 2005, str. 122-128.

Africa development indicators 2008/09: youth and employment in Africa, Washington 2009.

Africa - Up in Smoke, London 2005.

African lands: Challenges from Angola to Zimbabwe, (ur. Buckley, R.), Cheltenham 2005.

AIDS Epidemic Update, Geneva 2007.

Assessing Progress in Africa towards the Millennium Development Goals 2008, Adis Ababa 2009.

Atlas der Globalisierung, Berlin 2003.

de Blij, H. J., Muller, P. O., Geography: Realms, Regions, and Concepts, New York 1997.

Global Environmental Outlook 3: Past, present and future perspectives, Nairobi 2002.

Gupta, S., Yang, Y., Unblocking Trade, Finance \& Development, 4, 2006, URL: http://www.imf.org/external/pubs/ft/fandd/2006/12/index.htm $<4.8 .2009>$.

Hardi, P. In drugi, Measuring Sustainable Development: Review of Current Practice, Ottawa 1997.

Human Development Report 2003, New York 2003.

Human Development Report 2005, New York 2005.

Human Development Report 2007/2008, New York 2007.

Indicators of Sustainable Development: Guidelines and Methodologies, New York 2001.

Living Planet Report 2008, Gland 2008. 
Mbeki, M., Underdevelopment in sub-Saharan Africa, Foreign Policy Briefing 82, 2005.

Medved, J., Afrika, Ljubljana 1978.

Pulsipher Mihelič, L., Pulsipher, A., World Regional Geography: Global Patterns, Local Lives, New York 2002.

Road map towards the implementation of the United Nations Millennium Declaration, New York 2001.

Soubbotina, T. P., Sheram, K. A., Beyond economic growth: meeting the challenges of global development, Washington 2000.

Stern, N., Stern Review: The Economics of Climate Change, 2006, URL: http://www.hm-treasury.gov.uk/sternreview_index.htm <26. 7. 2009>.

Stock, R., Africa South of the Sahara: A Geographical Interpretation, New York, London 2004.

The Millennium Development Goals Report 2005, New York 2005.

The Millennium Development Goals Report 2008, New York 2008.

The World Health Report 2004: Changing history, Genova 2004.

UNPD - United Nations Population Division. World Population Prospects: the 2004 Revision, 2005, URL: http://www.un.org/esa/population/publications/publications.htm $<18.1 .2006>$.

Vintar Mally, K., Države v razvoju - med okoljevarstvom in razvojnimi težnjami, Ljubljana 2009.

World Development Indicators 2008, Washington 2008.

World Development Report 2003: Sustainable Development in a Dynamic World, New York 2003.

World Malaria Report 2008, Geneva 2008. 


\section{SUB-SAHARAN AFRICA'S LAGGING DEVELOPMENT}

Key Words: sub-Saharan Africa, developing countries, Millennium Development Goals, regional geography

\section{Abstract}

Sub-Saharan Africa is a very diverse region with extensive natural wealth, great human potential, and a rich history. However, the majority of its countries are among the poorest in the world and about half of its 800 million inhabitants live in extreme poverty. Sub-Saharan Africa produces only $1.5 \%$ of the world's GDP and its share in world trade has fallen from $6 \%$ in 1980 to $2 \%$ today. The region's exports remain dominated by primary goods (fuels, ores, and agricultural products). The roots of the region's economic weakness lie variously in the past colonial relationships with European countries and in unjust global trade patterns as well as in misuse of power by ruling political elites in the post-independence era. Numerous civil wars and other conflicts have fragmented the sub-Saharan countries into many factions and parties fighting for domination. The region is lagging behind developed countries because of corruption, lack of infrastructure, weakness of its institutions, heavy indebtedness, lack of education and health services, and unfavorable natural conditions, among other factors. Subsistence agriculture is the source of livelihood for most Africans. Nevertheless, average yields per hectare are low and heavily dependent on climatic conditions. Compared to urban areas (except for slums), people living in rural areas have worse infrastructure and are further from achieving the UN's Millennium Development Goals. The recent increase in food prices is threatening the limited progress in reducing hunger and malnutrition (28\% of children under age five are underweight and particularly vulnerable to infectious diseases). Little progress has been made in reducing child and maternal mortality; mortality rates remain the highest in the world. In the previous decade, life expectancy in sub-Saharan countries has fallen due to the spread of HIV/AIDS and it still remains below fifty. In addition, 
many negative socioeconomic effects are the result of malaria, which kills approximately one million people every year, $91 \%$ of whom live in sub-Saharan Africa. In order to promote gender equality and empower women, education is of vital importance. Compared to other (especially developed) regions, school enrollment rates are considerably lower and dropout rates considerably higher, particularly for girls. The majority of countries in subSaharan Africa will not be able to achieve their educational goals by 2015 . Despite the fact that the region is not exceeding the carrying capacities of its environment (as measured by its ecological footprint), environmental problems in some areas are severe. Deforestation, desertification, coral bleaching, negative effects of climate changes (sea level rise, reduced freshwater availability, extreme weather events, etc.), loss of biodiversity, and soil degradation are the most worrying. Population growth is exacerbating these environmental problems and is making it more difficult to achieve a higher standard of living for all. Owing to the complexity of developmental problems, sub-Saharan Africa will have to use its own resources very wisely and make the most of development aid from developed countries. 